\title{
Perceptual and Acoustical Assessments on Spasmodic Dysphonia: Pre and Post - Botulinum Toxin Injection
}

Hartono Abdoerrachman

\begin{abstract}
Adductor spasmodic dysphonia is a vocal disorder of uncertain etiology with no satisfactory long-term treatment-result. Recently injection of Botulinum toxin (BOTOX) into the thyroarytenoid muscle has been used as an effective temporary treatment. In this experiment, 9 patients with adductor spasmodic dysphonia (SPD) were studied and injected percutaneously the Botulinum toxin with dose of injection ranges from 1.25 to 5 units totally. Post treatment results were monitored acoustically for objective voice analysis and auditorily for perceptual judgment. Temporary satisfactory results were obtained after the average of 2 months post-injection, and lasted for at least 5 months of average. The test of vocal controllability derived from several acoustic parameters extraction, e.g. the pitch perturbation quotient (PPQ), amplitude perturbation quotient $(A P Q)$, the Fo overall variability $(F o V)$, energy of slow and fast Fo perturbation (FOS and FOF), showed improvement on post-BOTOX injection, and illustrate the efficacy of the analysis system used.
\end{abstract}

\begin{abstract}
Abstrak
Disfonia adduktor spasmodik adalah kelainan suara yang etiologinya belum jelas, dengan hasil terapi jangka panjang yang tidak memuaskan. Dewasa ini injeksi toksin Botulinum (BOTOX) ke muskulus tiroaritenoid banyak diterapkan. Pada penelitian ini dilakukan studi pada 9 kasus disfonia adduktor spasmodik dengan menyuntikkan 1.25 sampai 5 unit BOTOX melalui kulit ke dalam otot laring. Hasil terapi dimonitor secara akustik untuk menganalisis suara secara objektif dan perseptual. Keberhasilan sementara didapatkan setelah kurang lebih 2 bulan pasca terapi, dan berlanjut sampai kurang-lebih 5 bulan. Tes kontrol suara yang dihimpun dari hasil beberapa parameter yang dihitung yaitu: pitch perturbation quotient (PPQ), amplitude perturbation quotient (APQ), Fo overall variability $(F o V)$, energy of slow and fast perturbation ( $F o S$ and $F o F)$ menunjukkan perbaikan yang bermakna pada grup pasca-BOTOX. Hal ini juga menggambarkan kinerja yang berdaya-guna dari sistem analisis suara yang dipakai.
\end{abstract}

Keywords: spastic dysphonia, voice analysis, vocal controllability.

Spasmodic dysphonia (SPD) is a central nervous system phenomenon of unknown etiology characterized by uncoordinated voice tremor with erratic patterns of laryngeal contraction. ${ }^{1}$

The uncertainty of the SPD etiology arose researchers to conduct experiments and options in the treatment of SPD patients to try to eliminate the disruptive voice symptoms. Such attempts were resection of a portion of the reccurent laryngeal nerve on one side, ${ }^{2} \mathrm{CO}_{2}$ laser resection of the thyroarytenoic, ${ }^{3}$ anterior laryngoplasty, voice therapy, pharmacotherapy, and the most promising one is Botulinum toxin injection.

Eventhough most of opinions declared that adductor SPD was a vocal disorder with no satisfactory longterm treatment-result, many experiments had been

Department of Otorhinolaryngology, Faculty of Medicine, University of Indonesia/Dr. Cipto Mangunkusumo Hospital, Jakarta, Indonesia conducted. Woodson et $\mathrm{al}^{4}$ reported a study on the effects of Botulinum toxin therapy in patients with adductor SPD in term of acoustic, aerodynamic and videoendoscopy findings, and concluded a successful result on post-therapy condition. Adams et al ${ }^{5}$ reported a study concerning unilateral versus bilateral Botulinum toxin injections in SPD for acoustic and perceptual results and concluded that unilateral BOTOX injections may provide both superior and longer lasting benefits than bilateral BOTOX injections. Green et al ${ }^{6}$ reported his method of point-touch technique of Botulinum toxin injection for the treatment of SPD by means of flexible nasopharyngeal endoscopy guidance. Kobayasi et $\mathrm{al}^{7}$ also reported his successful method for percutaneus insertion technique of the needle for injecting the Botulinum toxin into the thyroarytenoid muscle of SPD patients.

Botulinum toxin is produced by the anaerobic bacterium Clostridium botulinum, and causes temporary paralysis by blocking the presynaptic release of acetyl- 
choline at the neuromuscular junction. This action is clinically used to alleviate muscle spasm by injecting the toxin directly into the overactive muscle.

Despite so many experiments and researches has been done concerning SPD, there are still many unanswered questions, and the field for investigations and researches in SPD remains widely open.

In this study, experiment was conducted upon adductor SPD patients, and injection of Botulinum toxin was performed using percutaneus technique of needle insertion into the thyroarytenoid muscle. Auditory perceptual were done subjectively by the patients themselves and objectively by the doctor. Besides, acoustical analysis were also performed before and after treatment, to monitor the results as a follow up mean.

\section{MATERIALS AND METHOD}

This study was conducted in the Research Institute of Logopedics and Phoniatrics (RILP), Tokyo University, from 1995 through 1996 . The subjects for this experiment were 9 patients of adductor SPD, consisted of 2 males and 7 females with ages ranged from 20 to 71 years, who had been suffering from the disease for more than six months. The control group voice samples were obtained from 15 normal speakers aged 26 to 67 years. The normal/healthy voices were the modal voice samples produced at most comfortable level and pitch by healthy speakers, without any history of pathology affecting phonation.

BOTOX injection were performed using percutaneus procedure, and the technique is identical to electromyography of the vocal folds. A 23-gauge hypodermic needle, coated with Teflon except for its tip, was used both as a monopolar electrode to locate the vocal folds and as an injection channel. The needle was inserted percutaneusly through the crycothyroid membrane, and correct positioning of the needle was confirmed by EMG display or audiomonitoring on phonation.

Voice samples collection were performed by recording sustained vowel /a/ produced by subjects as long as they were able to, at their most comfortable level and pitch. SPD voice samples were obtained before (preBOTOX) and about 2 months after (post-BOTOX) BOTOX injection.

Recordings were made using DAT tape-recorder, with a constant distance of $15 \mathrm{~cm}$, between microphone and mouth, following repeated patient's practice, and recordings were made in sound attenuated room. Voice samples of sustained vowel /a/ were then digitalized through a 16-bit A/D converter at a sampling rate of 40 $\mathrm{kHz}$ and stored on a disk controlled by computer. The acoustic feature of a voice sample was analyzed using the "SONG" computer aided program.

Using waveform matching and peak picking method, the method proposed by Imaizumi et al, ${ }^{8,9}$ local maximum points which could correspond to vocal excitation epochs were detected successively and then two time series of Fo(i) and A(i), the fundamental frequency and the maximum amplitude of $\mathrm{i}$-th glottal period were determined. Cycle-by-cycle perturbation quotient were calculated, pitch perturbation quotient (PPQ) and amplitude perturbation quotient (APQ) and several voice properties were extracted such as the overall variability of Fo (FoV), the additive noise level (Noise Level), and the energy of slow and fast Fo perturbations (FoS and FoF).

Two kinds of scoring were applied to assess the voice condition auditorily: appraisement by the patients themselves depending on their feeling, called as "subjective scaling". The scores ranged between 0 (for no complaints on phonation, no difficulty, smooth, the voice seemed regular and not disruptive), up to 3 [for difficult feeling on phonation, straining, and no change compared to before injection (pre-BOTOX)]. In between there were better conditions of voices, score 1 (much better than before injection) and 2 (better than before).

The "perceptual objective scaling" was a scoring method performed by the doctor using 25 morae. The score depends upon how many morae could be well pronounced by the patients. Scaling ranged between 25 for bad condition with no mora pronounced clearly, smoothly, regularly and without voice stops, up to 0 for normal condition, the whole 25 morae were pronounced smoothly, effortless and without voice stops.

For statistical calculation, an analysis of variance (ANOVA) with one factor, the group, was performed to determined significance.

\section{RESULTS}

The acoustic feature of a voice sample analyzed using the "SONG" computer aided program was consisted of 5 panels and showed on figure 1 . 


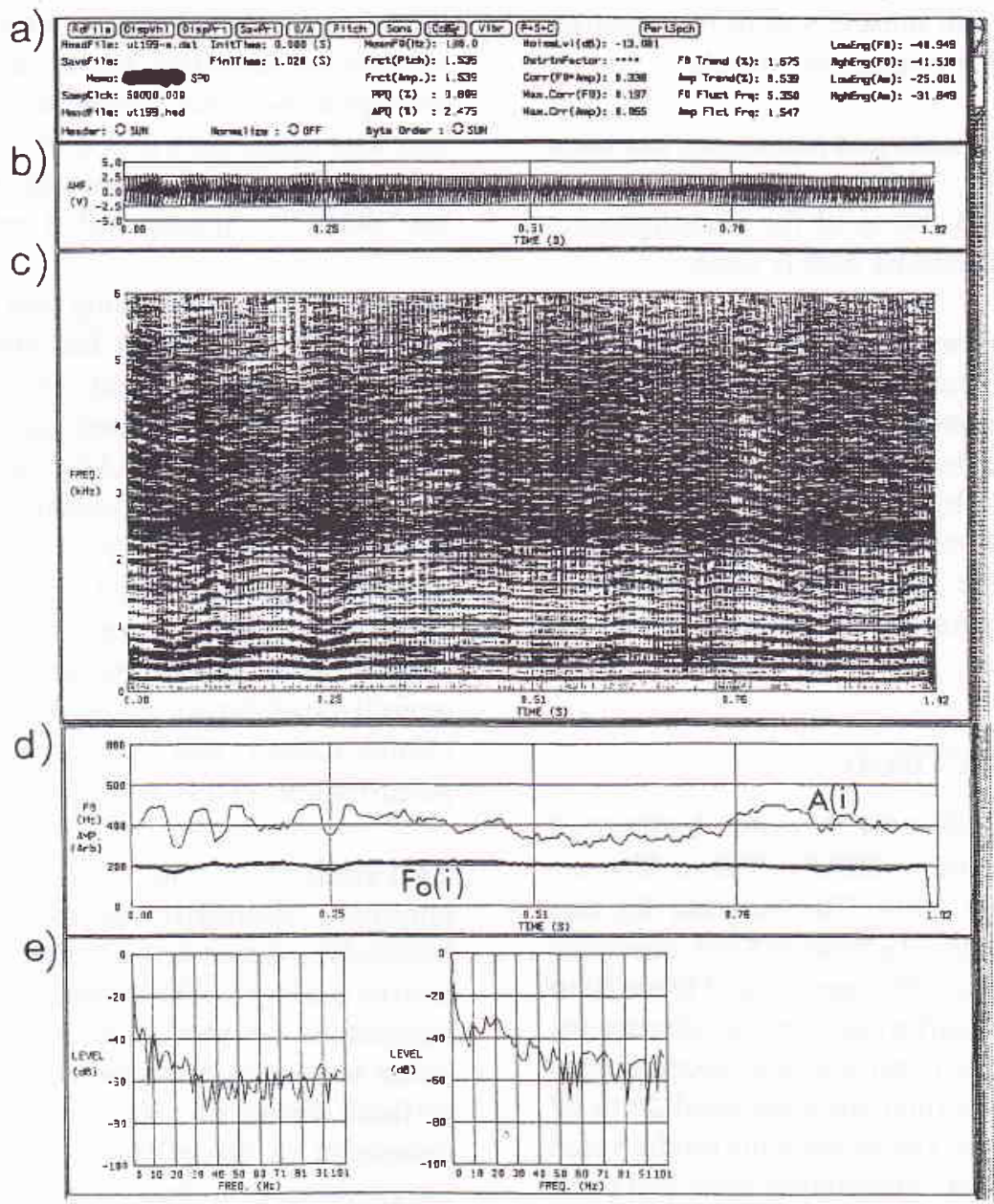

Figure 1. The acoustic feature of a voice sample analyzed by "SONG" computer-aided program. a) display of analysis conditions and results, $b$ ) the voice waveform, $c$ ) the sound spectogram, d) Fo and amplitude time series calculated using the acoustic analysis, $e)$ the power spectrum of $F o(i)$ and $A(i)$.

The bar plot of the Log 10 pitch perturbation quotient (PPQ) for the whole groups was showed in figure 2. The mean value of PPQ before injection was -0.061 (SD 0.718). This mean value was decreased to -0.533 (SD. 0.331) after injection, but the normal control group had the lowest mean value $(-0.897$, SD 0.246). Statistical analysis showed that post-BOTOX injection the PPQ was decreased significantly $(P<0.0001)$, but still higher compared to normal voices.

The bar plot of Log 10 amplitude perturbation quotient (APQ), for the whole groups was showed in figure 3. After injection, the APQ (mean value 0.379, SD 0.379) was unsignificantly decreased $(P>0.005)$ compared to before injection (mean value 0.401 , SD 0.374). However, compared to the normal control (mean 0.142, SD $0.246)$ the difference is significant $(P<0.0001)$.
Figure 4 showed the bar plot of the overall variability of $F_{0}\left(F_{0} V\right)$, indicating that after injection of BOTOX the $F_{0} V$ (mean value 2.839 , SD 5.685) was decreased significantly $(P<0.0001)$ compared to before injection (mean value19.870, SD 25.878), but still larger compared to normal voices (mean 0.830 , SD 0.467).

Figure 5 showed the bar plot of the energy of slow $F_{0}$ perturbation $\left(\mathrm{F}_{\mathrm{o}} \mathrm{S}\right)$, revealing the significant decrease $(P<0.0001)$ in the strength of $\mathrm{F}_{\mathrm{O}} \mathrm{S}$ on post-BOTOX injection (mean value -42.560 , SD 8.772) compared to pre-BOTOX injection (mean value -32.200 , SD 16.775), but still stronger compared to normal group (mean -46.503, SD 4.393). 


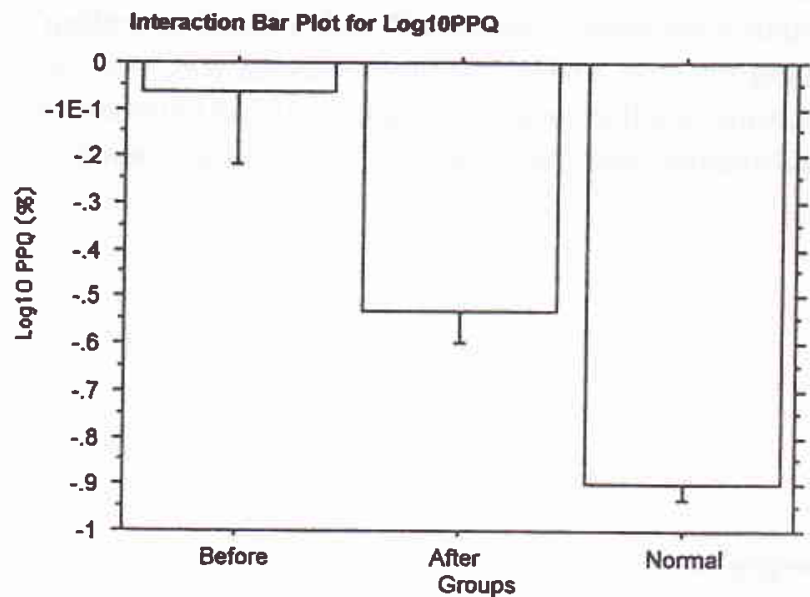

Figure 2. The bar plot of Log 10 pitch perturbation quotient (PPQ) for the whole groups.

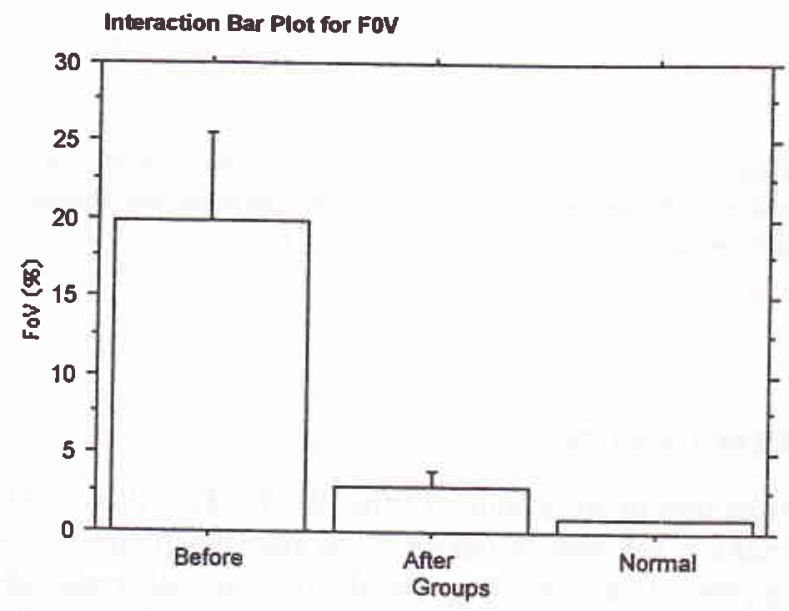

Figure 4. The bar plot of the overall variability of $F_{o}\left(F_{0} V\right)$ for the whole groups.

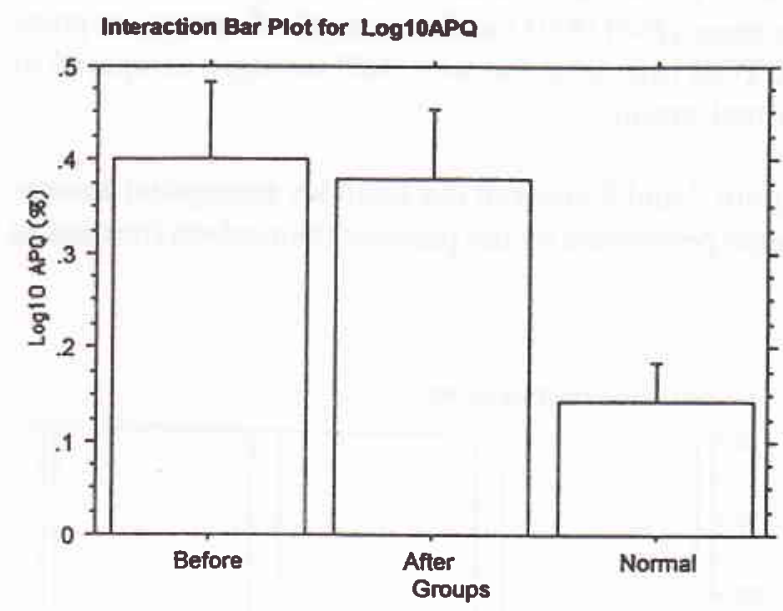

Figure 3. The bar plot of Log 10 APQ for the whole groups.

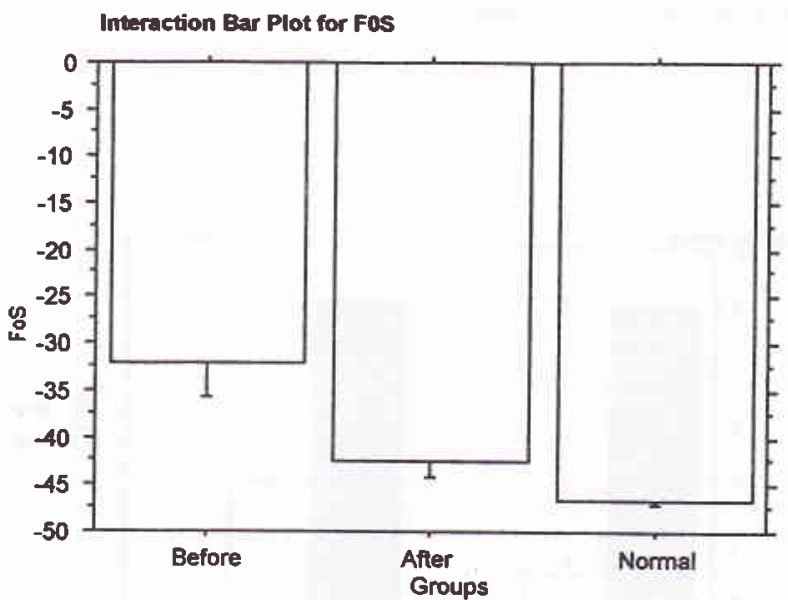

Figure 5. The bar plot of the energy of Slow $F_{c}$. Perturbation (FoS) for the whole groups. 
Figure 6 showed the bar plot of the energy of fast $F_{0}$ perturbations $\left(\mathrm{F}_{0} \mathrm{~F}\right)$. The mean $\mathrm{F}_{0} \mathrm{~F}$ value of preBOTOX injection was -39.140 (SD 17.674). This was -49.171 (SD 7.062) in post-BOTOX, and -56.689 (SD $4.667)$ in normal control indicating the significant decrease $(P<0.0001)$ in the strength of energy on postBOTOX injection, but were still stronger compared to normal group.

Figure 7 and 8 showed the auditory perceptual assessments performed by the patients themselves (termed as

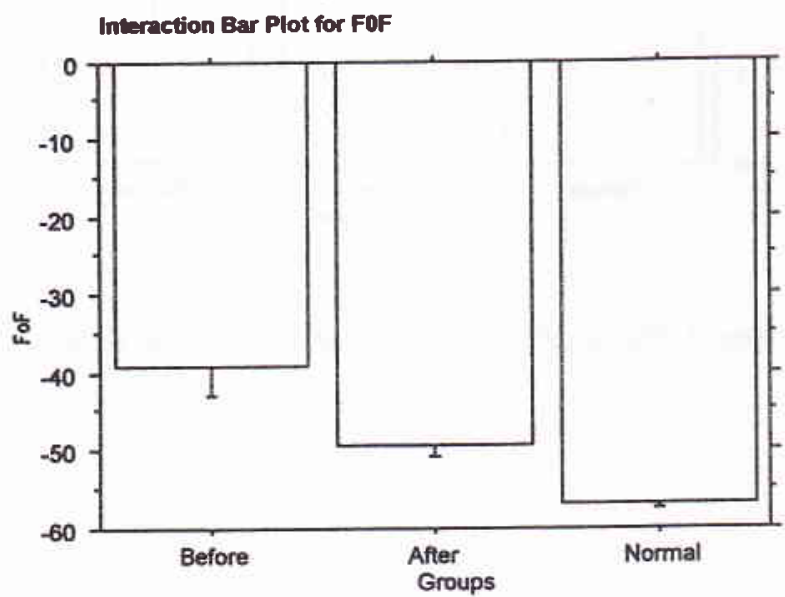

Figure 6. The bar plot of the energy of fast $F_{o}$ perturbation $\left(F_{o} F\right)$ for the whole groups.

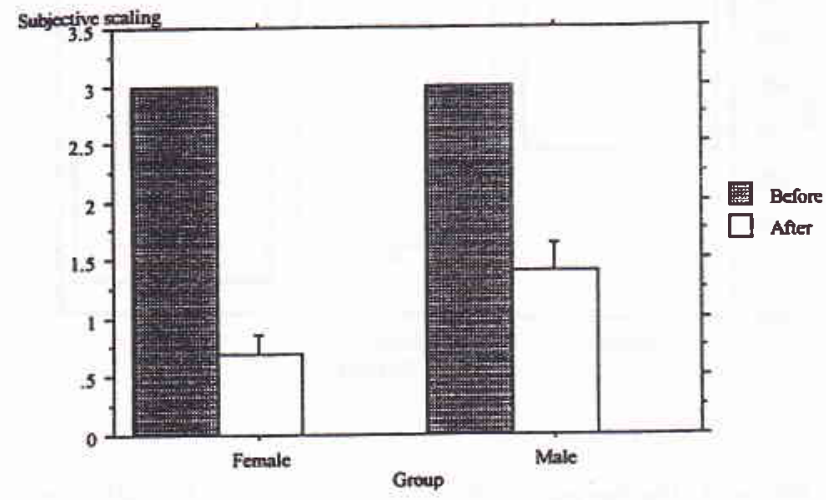

Figure 7. The bar plot of perceptual "Subjective scaling" of voice condition performed by male and female SPD patients themselves, before and after BOTOX injection. the "subjective perceptual scaling") and by the doctor (termed as "objective perceptual scaling"). Statistically, the scores on post-BOTOX injection were significantly decreased $(P<0.0001)$ compared to the scores on pre-BOTOX injection. Moreover, the correlation between "subjective" and "objective scaling" using Pearson's $95 \%$ confident interval was $91 \%$, indicating that there was a strong correlation between the "subjective" and the "objective" perceptual scaling.

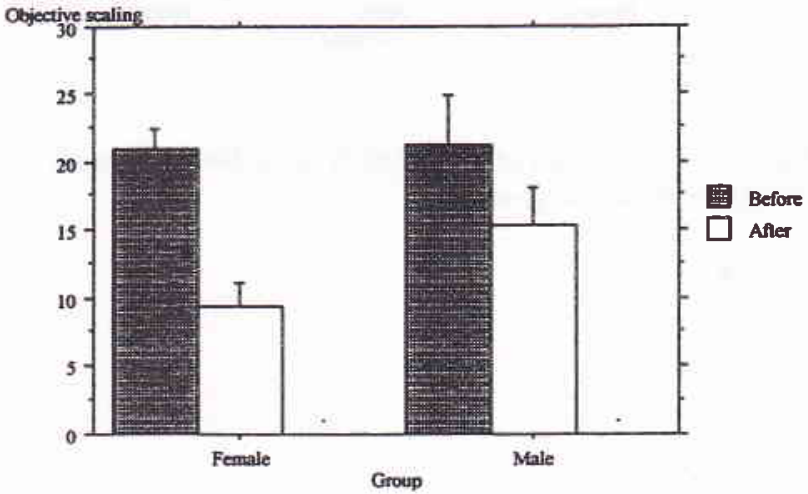

Figure 8. The bar plot of perceptual "Objective scaling" of voice condition performed by the doctor on male and female $S P D$ patients, before and after BOTOX injection.

\section{DISCUSSION}

Injection of Botulinum Toxin (BOTOX) is directed to make a temporary paralysis or paresis of the thyroarytenoid muscle. The paralysis will decrease the muscular spasm that causes uncontrolled muscular contraction on phonation, and resulted in better condition for vibration. The situation was clearly seen in the compared results of analyzed voice samples of preBOTOX versus post-BOTOX injections, by assessing the voice conditions acoustically and perceptually. Temporary satisfactory results were obtained after the average of 2 months, and lasted for at least 5 months. 
From the results obtained, it can be seen that all the parameters of voice perturbations extracted e.g.: the pitch perturbation quotient, the amplitude perturbation quotient, the overall variability of Fo, the energy of slow perturbation of Fo and the energy of fast perturbation of Fo showed a decrease in post-BOTOX voices, indicating that post-BOTOX patients had better Fo control compared to Pre-Botox patients, and the voices were less fluctuating and more stable. In other words, post-BOTOX patients had better vocal controllability than pre-BOTOX. The results were in accordance to other experts' reports e.g. Zwirner et al., ${ }^{10}$ and Woodson et al. 4 They found similar tendencies on post-BOTOX condition, although they did not compare with Normal speakers.

The APQ was not significantly decreased on postBOTOX, this phenomenon was probably due to several reasons: the SPD subjects were mostly consisted of female patients ( 7 out of 9 speakers), and the female patients have a tendency to produce higher frequency and intensity on sustained vowel phonation. This condition will be resulting in reduced perturbations.

Although Post-BOTOX patients regained their voices, but compared to normal speakers, their voices have larger perturbations.

Subjective feeling and perceptual assessments of SPD voices which were performed both by the patients themselves as "subjective scaling" and by the doctor as "objective scaling", showed that on post-BOTOX the voice conditions were better and the scaling decreased significantly. Correlation calculation (Pearson's) between those 2 scalings showed strong correlation $(=0.906)$, suggested that those two assessments were parallel.

\section{CONCLUSION}

1. Post-BOTOX voice samples showed a decrease in Fo perturbations, suggested that post-BOTOX group had better vocal controllability compared to pre-BOTOX group.

2. Although post-BOTOX group regained their voices, their perturbations were higher than normal voices, indicating that compared to normal voices the vocal controllability is lower.

3. The "subjective scale" and "objective scale" were decreased significantly on post-BOTOX group, and the two scoring scales were strongly correlated. This suggested that not only acoustically the post BOTOX group was improved, but perceptually as well.

\section{Acknowledgment}

This study was conducted in cooperation with the Research Institute of Logopedics and Phoniatrics, Fac. of Medicine, University of Tokyo and the author would like to express his gratitude and thanks for the supervision given by Prof. S. Niimi, Asc. Prof. S. Imaizumi and $\mathrm{M}$. Kumada MD.

\section{REFERENCES}

1. Broniatowski M, Davies CR, Jacobs GB, GrundfestBroniatowski S, Nose Y, Tucker HM. Electronic control of laryngeal spsm. Blockage of orthodromically induced action potentials in intact canine reccurent laryngeal nerve. Laryngoscope 1990;100(8):892-5.

2. Netterville JL, Stone RE, Rainey C, Zealear DL, Ossoff RH. Reccurent laryngeal nerve avulsion for treatment of spastic dysphonia. Ann Otol Rhinol Laryngol 1991;100(1):10-4.

3. Woo P. Carbon dioxide laser-assisted thyroarytenoid myomectomy. Lasers in Surgery \& Medicine 1990;10(5): 438-43.

4. Woodson GE. Effects of botulinum toxin therapy in patients with adductor spasmodic dysphonia: acoustic, aerodynamic, and videoendoscopic findings. Laryngoscope 1992;102(4): 400-6.

5. Adams SG, Hunt EJ, Charles DA, Lang AE. Unilateral versus bilateral botulinum toxin injections in spasmodic dysphonia: acoustic and perceptual results. J Otolaryngol 1993;22(3):171-5.

6. Green DC, Berke GS, Ward PH, Gerratt BR. Point-touch technique of botulinum toxin injection for the treatment of spasmodic dysphonia. Ann Otol Rhinol Laryngol 1992; 101(11):883-7.

7. Kobayashi T, Niimi S, Kumada M, Kosaki H, Hirose H. Botulinum toxin treatment for spasmodic dysphonia. Acta Oto-Laryngologica 1993;504(suppl):155-7.

8. Imaizumi S, Gauffin J. Acoustical perceptual characteristics of Pathological Voices: rough, creak, fry, and diplophonia. Ann Bull RILP 1991;25:109-19.

9. Imaizumi S, Abdoerrachman H, Niimi S, Shimura Y, Saida H. Evaluation of vocal controllability by an object-oriented acoustic analysis system. J Acoust Soc Jpn (E) 1994;15(2):113-16.

10. Zwimer P, Murry T, Swenson M, Woodson G. Acoustic changes in Spasmodic Dysphonia After Botulinum Toxin Injection. J Voice 1991;5(1): 78-84. 